\title{
Preoperative Plasma Aldosterone Predicts Complete Remission of Type 2 Diabetes after Bariatric Surgery
}

\author{
Masahiro Ohira $^{a}$ Kazuki Abe $^{\mathrm{b}}$ Takashi Yamaguchi $^{\mathrm{b}}$ Hiroki Onda $^{\mathrm{b}}$ \\ Shuhei Yamaoka ${ }^{b}$ Shoko Nakamura ${ }^{b}$ Shou Tanaka ${ }^{b}$ Yasuhiro Watanabe $^{b}$

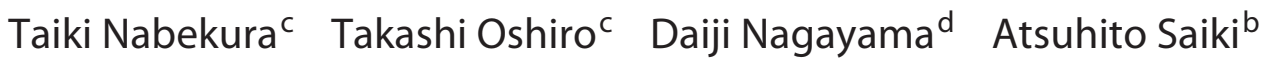 \\ Ichiro Tatsuno ${ }^{\mathrm{b}, \mathrm{e}}$
}

aDivision of Diabetes, Metabolism and Endocrinology, Department of Internal Medicine, Toho University Ohashi Medical Center, Tokyo, Japan; ${ }^{\mathrm{b} C e n t e r}$ for Diabetes, Endocrine and Metabolism, Toho University Sakura Medical Center, Chiba, Japan; 'Department of Surgery, Toho University Sakura Medical Center, Chiba, Japan; dDepartment of

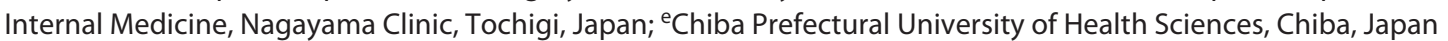

\section{Keywords}

Bariatric surgery · Type 2 diabetes · Plasma aldosterone concentration $\cdot$ Diabetes remission

\begin{abstract}
Introduction: Bariatric surgery (BS) has beneficial effects on body weight and type 2 diabetes. However, 44-52\%, 20$40 \%$, and $19-25 \%$ of patients with type 2 diabetes who undergo sleeve gastrectomy, sleeve gastrectomy with duodenal-jejunal bypass, and Roux-en-Y gastric bypass, respectively, show insufficient improvement 1 year after BS. It is thus important to predict the improvement in type 2 diabetes before BS. Many hormones are related to hyperglycemia. However, the relationship between hormones and improvement in type 2 diabetes after BS has not been studied. We aimed to evaluate the relationship between the improvement in type 2 diabetes and hormones in patients with obesity and type 2 diabetes who underwent BS. Methods: We retrospectively reviewed 79 patients with obesity and type 2 diabetes who underwent BS, with a follow-up period of 12 months.
\end{abstract}

We analyzed the relationship between some clinical parameters and complete remission (CR) of type 2 diabetes after BS. Patients were divided into two groups (type 2 diabetes $\mathrm{CR}$ and non-CR). Multiple regression analysis was performed to determine the parameters associated with type 2 diabetes resolution after BS. Results: BS significantly improved body weight and glucose metabolism. Preoperative liver function, glycated hemoglobin ( $\mathrm{HbA} 1 \mathrm{c})$, insulin secretion (homeostatic model assessment [HOMA]2-\%B), renin activity, plasma aldosterone level, and duration of type 2 diabetes were significantly different between the $C R$ and non-CR groups. Multiple regression analysis showed that preoperative $\mathrm{HbA} 1 \mathrm{c}, \mathrm{HOMA2} \% \mathrm{~B}$, aldosterone concentration, and duration of type 2 diabetes were predictors of CR of type 2 diabetes after BS. Plasma aldosterone was the strongest predictor. Discussion/Conclusion: Preoperative plasma aldosterone levels were related to the CR of type 2 diabetes after BS. Measuring plasma aldosterone levels preoperatively is useful for predicting the CR of type 2 diabetes after BS.

(c) 2022 The Author(s).

Published by S. Karger AG, Basel
(C) 2022 The Author(s)

Published by S. Karger AG, Basel

This is an Open Access article licensed under the Creative Common Attribution-NonCommercial-4.0 International License (CC BY-NC) (http://www.karger.com/Services/OpenAccessLicense), applicable to the online version of the article only. Usage and distribution for commercial purposes requires written permission.
Correspondence to:

Masahiro Ohira,600137om@ @akura.med.toho-u.ac.jp 


\section{Introduction}

Currently, bariatric surgery (BS) is the most effective weight loss therapy. It also has a positive effect on type 2 diabetes. BS significantly reduces glycated hemoglobin (HbA1c) levels compared to medical therapy alone $(-2.1 \%$ vs. $-0.3 \%$ at 5 years) [1]. Type 2 diabetes remission rates after $\mathrm{BS}$ at 2,10 , and 15 years are $72.3 \%, 38.1 \%$, and $30.4 \%$, respectively, which are significantly higher than those observed in controls [2]. Gastrointestinal therapeutic interventions, such as BS, for type 2 diabetes are classified as metabolic surgery [3, 4]; they improve glycemic control, as indicated by changes in HbAlc levels, which significantly decrease from 1 month after metabolic surgery and are maintained at $<6.0 \%$ after 12 months [5]. Metabolic surgery reduces macrovascular and microvascular complications and mortality, compared to medical treatment in patients with type 2 diabetes $[2,6]$. Thus, bariatric and metabolic surgery have excellent therapeutic effects on blood glucose control as well as diabetes complications in patients with type 2 diabetes.

Although bariatric and metabolic surgery are effective treatments for type 2 diabetes, $44-52 \%, 20-40 \%$, and $19-$ $25 \%$ of patients with type 2 diabetes who undergo sleeve gastrectomy (SG), SG with duodenal-jejunal bypass (DJB), and Roux-en-Y gastric bypass (RYGB), respectively, do not achieve remission of type 2 diabetes 1 year after bariatric and metabolic surgery [7-11]. Therefore, predicting type 2 diabetes remission after BS is important. Some clinical parameters have been reported as predictors of type 2 diabetes remission after BS [12-15]. We previously reported that preoperative serum insulin-like growth factor-1 (IGF-1) is a predictor of weight reduction after laparoscopic SG [16]. Our previous report indicated that preoperative hormones predict changes in clinical parameters after BS.

Some hormones are related to hyperglycemia. For instance, cortisol and growth hormones are important hyperglycemic factors $[17,18]$, and aldosterone is associated with insulin sensitivity and secretion [19]. These hormones may predict type 2 diabetes remission after BS. However, the relationship between type 2 diabetes and hormones in patients with obesity and type 2 diabetes who undergo BS has not been reported. Assessing the relationship between blood glucose and hormones in patients with obesity who undergo BS can aid the postoperative treatment of type 2 diabetes. Therefore, the aim of this study was to investigate the relationship between type 2 diabetes and hormones in patients with obesity and type 2 diabetes who underwent BS.

\section{Materials and Methods}

\section{Study Design and Participants}

We retrospectively reviewed clinical data obtained from November 2010 to January 2020 at the Toho University Sakura Medical Center (Sakura City, Chiba, Japan) to identify patients with type 2 diabetes who were treated for primary obesity (BMI $\geq 32 \mathrm{~kg}$ / $\mathrm{m}^{2}$ at the first visit), who underwent BS, and were followed up for 12 months postoperatively. We excluded patients who could not be followed up for 12 months and those whose serum C-peptide level or visceral and subcutaneous fat area data at 12 months after BS were missing. The BMI criteria for BS in Japan are BMI $\geq 32 \mathrm{~kg} /$ $\mathrm{m}^{2}$ with at least one obesity-related comorbidity such as type 2 diabetes, hypertension, or hyperlipidemia and BMI $\geq 35 \mathrm{~kg} / \mathrm{m}^{2}$, according to the guidelines of the Japanese Society for Treatment of Obesity. Of the patients with type 2 diabetes, 93 underwent BS during this period, and 6 dropped out within 12 months after BS. Serum C-peptide level and/or abdominal fat area were not measured for 8 patients at 12 months after BS. Overall, 14 patients were excluded from this study, and $84.9 \%(n=79)$ of patients with type 2 diabetes who underwent BS at our hospital were included. The surgical procedures included SG $(n=62,78.5 \%)$, gastric bypass (GB) $(n=3,3.8 \%)$, and SG with DJB $(n=14,17.7 \%)$. Patients with a BMI $\geq 35 \mathrm{~kg} / \mathrm{m}^{2}$ whose ABCD scores were below 5 or insulin users who could afford for a procedure that was more expensive (8,000 USD) than SG (800 USD) were eligible for SG with DJB [20]. Patients with a BMI $\geq 35 \mathrm{~kg} / \mathrm{m}^{2}$ or $\mathrm{BMI} \geq 32 \mathrm{~kg} / \mathrm{m}^{2}$ with more than two obesity-related comorbidities and who could afford for a procedure that was more expensive (14,000-19,000 USD) than SG and SG with DJB were eligible for GB [20]. The other patients underwent SG because only SG is covered by the Japanese public medical insurance. We defined complete remission (CR) of type 2 diabetes as $\mathrm{HbA} 1 \mathrm{c}<6.0 \%$ without using any diabetes medication 12 months after BS, according to previous reports $[21,22]$.

We compared the following parameters before BS and 12 months after BS: body weight (BW), BMI, aspartate transaminase (AST), alanine transaminase (ALT), $\gamma$-glutamyl transpeptidase (GGT), cholinesterase (ChE), blood urea nitrogen (BUN), serum creatinine, estimated glomerular filtration rate (eGFR), total cholesterol, triglycerides (TG), high-density lipoprotein-cholesterol (HDL-C), low-density lipoprotein-cholesterol, fasting blood glucose (FBG), HbA1c, serum C-peptide, visceral fat area, subcutaneous fat area, steady state $\beta$-cell function homeostatic model assessment (HOMA)2 (HOMA2-\%B), insulin sensitivity HOMA2 (HOMA2-\%S), insulin resistance HOMA2 (HOMA2-IR), blood pressure (BP), and urinary albumin. The levels of serum growth hormone $(\mathrm{GH})$, serum IGF-1, plasma adrenocorticotropic hormone (ACTH), plasma cortisol, plasma renin activity, plasma aldosterone concentration (PAC), serum thyroid-stimulating hormone (TSH), serum free tri-iodothyronine (FT3), and serum free thyroxine (FT4) were measured at baseline to discriminate secondary obesity from secondary metabolic disorders. The total weight loss percentage (\%TWL) was estimated 12 months after BS. $\mathrm{BW}$ was measured, and blood samples were collected in the morning after a 12 -h fast.

\section{Measurements of Various Parameters}

Within $1 \mathrm{~h}$ of blood collection, the serum and plasma were separated by centrifuging the specimen at $3000 \mathrm{rpm}$ for $10 \mathrm{~min}$. The serum and plasma were used to measure HbA1c, AST, ALT, GGT, 
ChE, BUN, creatinine, eGFR, lipid, C-peptide, and hormone levels. Serum GH and plasma ACTH levels were measured by electrochemiluminescence immunoassay (ECLIA) using the ECLusys ${ }^{\circledR}$ reagent hGH or ECLusys ${ }^{\circledR}$ reagent ACTH assay kit (Roche Diagnostics, Basel, Switzerland). Serum IGF-1 levels were measured byimmunoradiometricassay using the ECLusys ${ }^{\circledR}$ reagent IGF-1 assay kit (Roche). Plasma cortisol, serum TSH, serum FT3, and serum FT4 levels were measured by chemiluminescence immunoassay (CLIA) using the Cortisol Abbott, ARCHITECT TSH, FT3 Abbott, or FT4 Abbott (Abbott, Chicago, IL, USA). ECLIA was performed using cobas8000 (Roche Diagnostics, Basel, Switzerland). CLIA was performed using Architect i2000 SR (Abbott). Plasma renin activity was measured by enzyme immunoassay (EIA) using the YAMASA ${ }^{\circledR}$ Renin Activity Kit (YAMASA CORPORATION, Chiba, Japan). PAC was measured by radioimmunoassay (RIA) using the SPAC-S Aldosterone kit ${ }^{\circledR}$ (Fujirebio, Tokyo, Japan). EIA was performed using AP-X (Hitachi Chemical Company Ltd., Tokyo, Japan). RIA was performed using an ARC950 $\gamma$ counter (Hitachi Ltd.). GH, IGF-1, ACTH, cortisol, aldosterone, and renin activity were measured at LSI Medience Corporation, Tokyo, Japan. TSH, FT3, and FT4 levels were measured at the Toho University Sakura Medical Center, Chiba, Japan. Visceral fat area was determined using computed tomography, which was performed at the umbilical level with the participant resting in the supine position. The subcutaneous fat area was calculated by subtracting the visceral fat area from the total fat area. Radiologists quantified the fat area using Ziostation2 software version 2.9.7.1 (Ziosoft, Inc., Tokyo, Japan).

\section{Calculation of HOMA2-\%B, HOMA2-\%S, and HOMA2-IR}

We used HOMA2, the updated HOMA model, to evaluate insulin secretion and resistance in this study. HOMA2 can account for variations in hepatic and peripheral glucose resistance [23]. HOMA2-\%B, HOMA2-\%S, and HOMA2-IR were determined using the HOMA2 Calculator (Oxford Centre for Diabetes, Endocrinology and Metabolism, Oxford, United Kingdom). Glucose (mg/ $\mathrm{dL}$ ) and serum C-peptide (ng/mL) levels were used to calculate the HOMA2 score.

\section{Statistical Analysis}

The normality of data distribution was tested using the Shapiro-Wilk test. Continuous data are expressed as median and interquartile range (IQR), as many data were nonnormally distributed. Data were analyzed using the Wilcoxon signed-rank test (paired samples) or Wilcoxon rank-sum test (independent samples). Fisher's exact test was used to identify significant differences between the proportions and categorical variables. The $\chi^{2}$ test was used to compare the three variables. Simple linear regression analysis was performed to analyze the correlation between CR of type 2 diabetes after BS and clinical parameters using Spearman's rank correlation coefficient, due to the nonparametric nature of all data. Multiple regression analysis was used to analyze the independent associations of variables with $\mathrm{CR}$ of type 2 diabetes. For correlation analyses, the presence or absence of CR in type 2 diabetes was coded as 1 and 0 , respectively. Sensitivity and specificity with respect to CR of type 2 diabetes were analyzed using conventional receiver operating characteristic (ROC) curves. Statistical significance was set at $p<0.05$. All statistical analyses were performed using JMP software (version 14.3.0; SAS, Cary, NC, USA).

\section{Results}

\section{Baseline Characteristics and Changes in Various}

Parameters 12 Months after BS

Table 1 shows the patients' baseline characteristics and changes in various parameters 12 months after BS. The median (IQR) age, BMI, and HbA1c were 44.0 (37.0$50.0)$ years, $43.1(37.8-50.3) \mathrm{kg} / \mathrm{m}^{2}$, and $6.8(6.4-8.1) \%$, respectively. At 12 months after $B S$, the CR rate of type 2 diabetes was $64.6 \%(n=51)$, and the median (IQR) \% TWL was $27.4(20.6-34.1 \%)$. The BW, BMI, and levels of visceral and subcutaneous fat significantly decreased after BS $(p<0.0001)$. TG, HDL-C, FBG, HbA1c, HOMA2-\%S, HOMA2-IR, and urinary albumin levels also significantly improved. Serum C-peptide levels significantly decreased. Systolic and diastolic BP did not significantly change after BS.

\section{Comparisons between Participants with and without CR of Type 2 Diabetes after BS}

We divided all participants into two groups based on CR of type 2 diabetes after BS: CR and non-CR groups. Fifty-one (64.6\%) and 28 (35.4\%) patients were included in the CR and non-CR groups, respectively. The rates of surgical procedures, median age, and BMI did not differ between the two groups. AST, ALT, and GGT levels were significantly higher in the CR group than in the non-CR group. HbA1c was significantly lower and HOMA2-\%B was significantly higher in the CR group than in the nonCR group (HbAlc: $6.6 \%$ [6.3\%-7.0\%] vs. $7.5 \%$ [6.7\%9.4\%], $p=0.0048 ;$ HOMA2-\%B: 102.5\% [77.2\%-121.9\%] vs. $87.2 \%$ [60.1\%-106.8\%], $p=0.0187$; Table 2). Renin activity and PAC were significantly lower in the CR group (renin activity: 1.9 [0.7-5.9] ng/mL/h vs. 3.5 [1.6-13.7] $\mathrm{ng} / \mathrm{mL} / \mathrm{h}, p=0.0219 ;$ PAC: 123.0 [94.0-160.0] $\mathrm{pg} / \mathrm{mL}$ vs. 175.0 [134.0-250.3] pg/mL, $p=0.0002$; Table 2). The duration of type 2 diabetes was significantly shorter in the CR group than in the non-CR group (4.0 [2.0-10.0] years vs. $10.5[4.5-15.0]$ years, $p=0.0063$; Table 2$)$. Other parameters were not significantly different between the groups.

\section{Correlation between CR of Type 2 Diabetes (No, 0 ;}

Yes, 1) and Each Clinical Parameter at Baseline

Table 3 shows the correlation between CR of type 2 diabetes (no, 0; yes, 1) and each clinical parameter at baseline. AST, ALT, GGT, and HOMA2-\%B showed a significant positive correlation with $\mathrm{CR}$ of type 2 diabetes after BS (AST: $\rho=0.2711, p=0.0157$; ALT: $\rho=0.2873$, $p=0.0102$; GGT: $\rho=0.3041, p=0.0064$; HOMA2-\%B: 
Table 1. Baseline characteristics and changes in various parameters 12 months after bariatric surgery

\begin{tabular}{|c|c|c|c|}
\hline & Baseline & After 12 months & $p$ value $^{a}$ \\
\hline Subjects, $n$ & 79 & - & - \\
\hline Sex (male/female) & $39(49.4 \%) / 40(50.6 \%)$ & - & - \\
\hline $\begin{array}{l}\text { Sleeve gastrectomy/gastric bypass/sleeve gastrectomy with } \\
\text { duodenal-jejunal bypass, } n(\%)\end{array}$ & $62(78.5) / 3(3.8) / 14(17.7)$ & - & - \\
\hline Complete remission of type 2 diabetes, $n(\%)$ & - & $51(64.6)$ & - \\
\hline $\mathrm{BW}, \mathrm{kg}$ & $113.8(99.0-143.6)$ & $82.0(71.3-101.7)$ & $<0.0001$ \\
\hline $\mathrm{BMI}, \mathrm{kg} / \mathrm{m}^{2}$ & $43.1(37.8-50.3)$ & $30.5(27.6-36.8)$ & $<0.0001$ \\
\hline AST, IU/L & $29.0(22.0-49.0)$ & $18.0(16.0-23.0)$ & $<0.0001$ \\
\hline ALT, IU/L & $37.0(22.0-66.0)$ & $17.0(13.0-23.0)$ & $<0.0001$ \\
\hline GGT, IU/L & $36.0(25.0-61.0)$ & $20.0(14.0-28.0)$ & $<0.0001$ \\
\hline ChE, IU/L & $383.0(338.0-438.0)$ & $319.0(269.0-359.0)$ & $<0.0001$ \\
\hline $\mathrm{TC}, \mathrm{mg} / \mathrm{dL}$ & $184.0(160.0-198.0)$ & $188.0(163.0-208.0)$ & 0.1110 \\
\hline $\mathrm{TG}, \mathrm{mg} / \mathrm{dL}$ & $145.0(115.0-191.0)$ & $85.0(61.0-130.0)$ & $<0.0001$ \\
\hline $\mathrm{HDL}-\mathrm{C}, \mathrm{mg} / \mathrm{dL}$ & $42.0(36.0-47.0)$ & $58.0(48.0-71.0)$ & $<0.0001$ \\
\hline $\mathrm{LDL}-\mathrm{C}, \mathrm{mg} / \mathrm{dL}$ & $111.0(95.0-135.0)$ & $108.0(92.0-126.0)$ & 0.1636 \\
\hline $\mathrm{FBG}, \mathrm{mg} / \mathrm{dL}$ & $120.0(105.0-154.0)$ & $103.0(92.0-112.0)$ & $<0.0001$ \\
\hline $\mathrm{HbA} 1 \mathrm{c}, \%$ & $6.8(6.4-8.1)$ & $5.8(5.4-6.1)$ & $<0.0001$ \\
\hline Serum C-peptide, ng/mL & $2.8(2.2-3.5)$ & $1.9(1.4-2.7)$ & $<0.0001$ \\
\hline HOMA2- $\%$ B, \% & 96.7 (73.4-114.9) & $91.2(73.2-121.1)$ & 0.4958 \\
\hline HOMA2-\%S, \% & $41.9(35.1-57.4)$ & $65.4(47.9-92.0)$ & $<0.0001$ \\
\hline HOMA2-IR & $2.39(1.74-2.85)$ & $1.53(1.09-2.09)$ & $<0.0001$ \\
\hline Systolic BP, mm Hg & $132.0(118.0-146.0)$ & $130.0(115.0-144.0)$ & 0.5576 \\
\hline Diastolic BP, mm Hg & $80.0(70.0-86.0)$ & $78.0(70.0-89.0)$ & 0.6194 \\
\hline Visceral fat area, $\mathrm{cm}^{2}$ & $209.0(159.0-250.1)$ & $109.2(70.1-149.4)$ & $<0.0001$ \\
\hline $\mathrm{TSH}, \mu \mathrm{IU} / \mathrm{mL}$ & $1.68(1.02-2.47)$ & - & - \\
\hline $\mathrm{FT} 3, \mathrm{pg} / \mathrm{mL}$ & $2.84(2.30-3.14)$ & - & - \\
\hline $\mathrm{FT} 4, \mathrm{ng} / \mathrm{dL}$ & $1.14(1.04-1.30)$ & - & - \\
\hline Duration of type 2 diabetes, years & $7.0(2.0-11.0)$ & - & - \\
\hline
\end{tabular}

Data are presented as median and interquartile range. TWL, total weight loss; BW, body weight; BMI, body mass index; AST, aspartate transaminase; ALT, alanine transaminase; GGT, $\gamma$-glutamyl transpeptidase; ChE, cholinesterase; BUN, blood urea nitrogen; eGFR, estimated glomerular filtration rate; TC, total cholesterol; TG, triglycerides; HDL-C, high-density lipoprotein-cholesterol; LDL-C, low-density lipoprotein-cholesterol; FBG, fasting blood glucose; HbA1c, glycosylated hemoglobin; HOMA, homeostatic model assessment; BP, blood pressure; $\mathrm{GH}$, growth hormone; IGF, insulin-like growth factor; ACTH, adrenocorticotropic hormone; TSH, thyroid-stimulating hormone; FT3, free

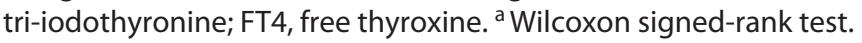

$\rho=0.2669, p=0.0174$; Table 3). HbA1c level, renin activity, PAC, and duration of type 2 diabetes were significantly negatively correlated with the $\mathrm{CR}$ of type 2 diabetes after BS (HbA1c: $\rho=-0.3202, p=0.0040$; renin activity: $\rho=-0.2600, p=0.0207 ;$ PAC: $\rho=-0.4259, p<0.0001$ duration of type 2 diabetes: $\rho=-0.3098, p=0.0055$; Table 3$)$. The other variables did not show any significant correlations. 
Table 2. Comparison of characteristics between participants with and without complete remission of type 2 diabetes (CR group and nonCR group)

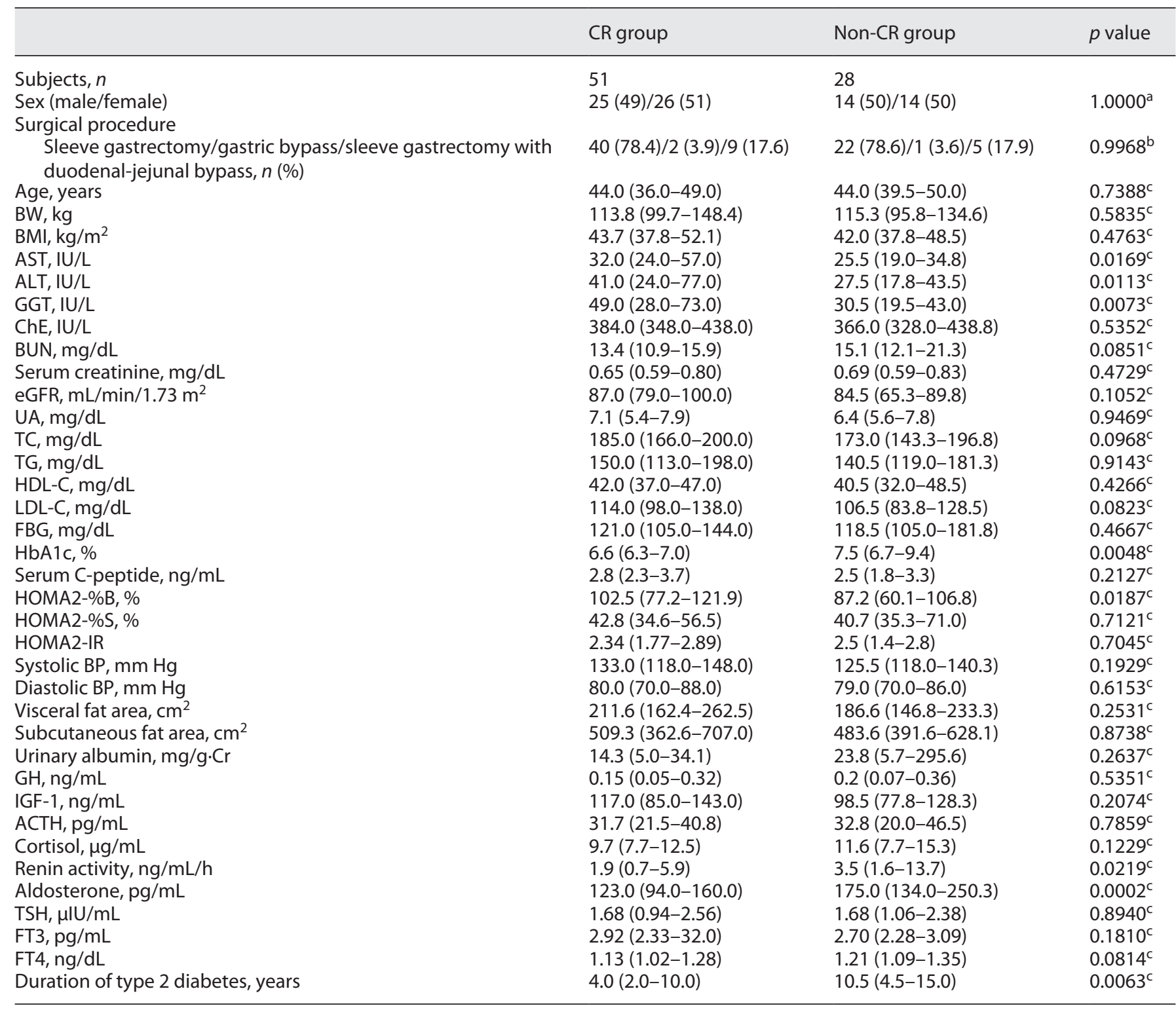

Data are presented as median and interquartile range. BW, body weight; BMI, body mass index; AST, aspartate transaminase; ALT, alanine transaminase; GGT, $\gamma$-glutamyl transpeptidase; ChE, cholinesterase; BUN, blood urea nitrogen; eGFR, estimated glomerular filtration rate; TC, total cholesterol; TG, triglycerides; HDL-C, high-density lipoprotein-cholesterol; LDL-C, low-density lipoprotein-cholesterol; FBG, fasting blood glucose; $\mathrm{HbA1c}$, glycosylated hemoglobin; HOMA, homeostatic model assessment; $\mathrm{BP}$, blood pressure; GH, growth hormone; IGF, insulin-like growth factor; ACTH, adrenocorticotropic hormone; TSH, thyroid-stimulating hormone; FT3, free tri-iodothyronine; FT4, free thyroxine. ${ }^{a}$ Fisher's exact test. ${ }^{b} X^{2}$ test. 'Wilcoxon signed-rank test.

\section{Association between CR of Type 2 Diabetes and Dependent Variables}

Baseline values of AST, ALT, GGT, HbA1c, HOMA2$\% \mathrm{~B}$, renin activity, $\mathrm{PAC}$, and duration of type 2 diabetes were significantly correlated with the CR of type 2 diabe- tes (Table 3). We excluded AST and ALT from the models because of their correlation with GGT levels. Although the duration of type 2 diabetes was intercorrelated with $\mathrm{HbA} 1 \mathrm{c}$ and HOMA2-\%B, it was included in the analysis because it significantly affects both islet func- 
Table 3. Correlation between complete remission of type 2 diabetes (no, $0 ;$ yes, 1) and each preoperative clinical parameter

\begin{tabular}{|c|c|c|}
\hline & \multicolumn{2}{|c|}{$\begin{array}{l}\text { Complete remission } \\
\text { of type } 2 \text { diabetes } \\
(\text { no, } 0 \text {; yes, } 1)\end{array}$} \\
\hline & $\rho$ & $p$ value \\
\hline Sex (male, 0 ; female, 1 ) & 0.0094 & 0.9346 \\
\hline Surgical procedure (sleeve, 0; bypass, 1) & 0.0016 & 0.9886 \\
\hline Age (years) & -0.0383 & 0.7373 \\
\hline $\mathrm{BW}(\mathrm{kg})$ & 0.0627 & 0.5832 \\
\hline BMI $\left(\mathrm{kg} / \mathrm{m}^{2}\right)$ & 0.0812 & 0.4767 \\
\hline AST (IU/L) & 0.2711 & 0.0157 \\
\hline ALT (IU/L) & 0.2873 & 0.0102 \\
\hline GGT (IU/L) & 0.3041 & 0.0064 \\
\hline ChE (IU/L) & 0.0708 & 0.5353 \\
\hline BUN $(\mathrm{mg} / \mathrm{mL})$ & -0.1956 & 0.0841 \\
\hline Serum creatinine (mg/mL) & -0.0818 & 0.4733 \\
\hline eGFR (mL/min/1.73 $\left.\mathrm{m}^{2}\right)$ & 0.1840 & 0.1045 \\
\hline $\mathrm{UA}(\mathrm{mg} / \mathrm{dL})$ & 0.0081 & 0.9433 \\
\hline $\mathrm{TC}(\mathrm{mg} / \mathrm{dL})$ & 0.1886 & 0.0960 \\
\hline $\mathrm{TG}(\mathrm{mg} / \mathrm{dL})$ & 0.0128 & 0.9111 \\
\hline $\mathrm{HDL}-\mathrm{C}(\mathrm{mg} / \mathrm{dL})$ & 0.0906 & 0.4272 \\
\hline LDL-C (mg/dL) & 0.1973 & 0.0813 \\
\hline $\mathrm{FBG}(\mathrm{mg} / \mathrm{dL})$ & -0.0830 & 0.4671 \\
\hline $\mathrm{HbA1c}(\%)$ & -0.3202 & 0.0040 \\
\hline Serum C-peptide (ng/mL) & 0.1417 & 0.2130 \\
\hline HOMA2-\%B (\%) & 0.2669 & 0.0174 \\
\hline HOMA2-\%S (\%) & -0.0424 & 0.7109 \\
\hline HOMA2-IR & 0.0435 & 0.7033 \\
\hline Systolic BP (mm Hg) & 0.1480 & 0.1930 \\
\hline Diastolic BP (mm Hg) & 0.0575 & 0.6148 \\
\hline Visceral fat area $\left(\mathrm{cm}^{2}\right)$ & 0.1300 & 0.2536 \\
\hline Subcutaneous fat area $\left(\mathrm{cm}^{2}\right)$ & 0.0186 & 0.8710 \\
\hline Urinary albumin $(\mathrm{mg} / \mathrm{g} \cdot \mathrm{Cr})$ & -0.1334 & 0.2641 \\
\hline $\mathrm{GH}(\mathrm{ng} / \mathrm{mL})$ & -0.0708 & 0.5352 \\
\hline IGF-1 (ng/mL) & 0.1433 & 0.2076 \\
\hline ACTH (pg/mL) & -0.0313 & 0.7840 \\
\hline Cortisol $(\mu \mathrm{g} / \mathrm{mL})$ & -0.1753 & 0.1224 \\
\hline Renin activity (ng/mL/h) & -0.2600 & 0.0207 \\
\hline Aldosterone $(\mathrm{pg} / \mathrm{mL})$ & -0.4259 & $<0.0001$ \\
\hline $\mathrm{TSH}(\mu \mathrm{IU} / \mathrm{mL})$ & -0.0157 & 0.8910 \\
\hline FT3 $(\mathrm{pg} / \mathrm{mL})$ & 0.1520 & 0.1810 \\
\hline $\mathrm{FT} 4(\mathrm{ng} / \mathrm{dL})$ & -0.1979 & 0.0804 \\
\hline Duration of type 2 diabetes (years) & -0.3098 & 0.0055 \\
\hline
\end{tabular}

Bypass refers to gastric bypass and sleeve gastrectomy with duodenal-jejunal bypass. BW, body weight; BMI, body mass index; AST, aspartate transaminase; ALT, alanine transaminase; GGT, $\gamma$-glutamyl transpeptidase; ChE, cholinesterase; BUN, blood urea nitrogen; eGFR, estimated glomerular filtration rate; TC, total cholesterol; $\mathrm{TG}$, triglycerides; HDL-C, high-density lipoprotein-cholesterol; LDL-C, low-density lipoprotein-cholesterol; FBG, fasting blood glucose; $\mathrm{HbA1c}$, glycosylated hemoglobin; HOMA, homeostatic model assessment; BP, blood pressure; $\mathrm{GH}$, growth hormone; IGF, insulin-like growth factor; ACTH, adrenocorticotropic hormone; TSH, thyroid-stimulating hormone; FT3, free tri-iodothyronine; FT4, free thyroxine.

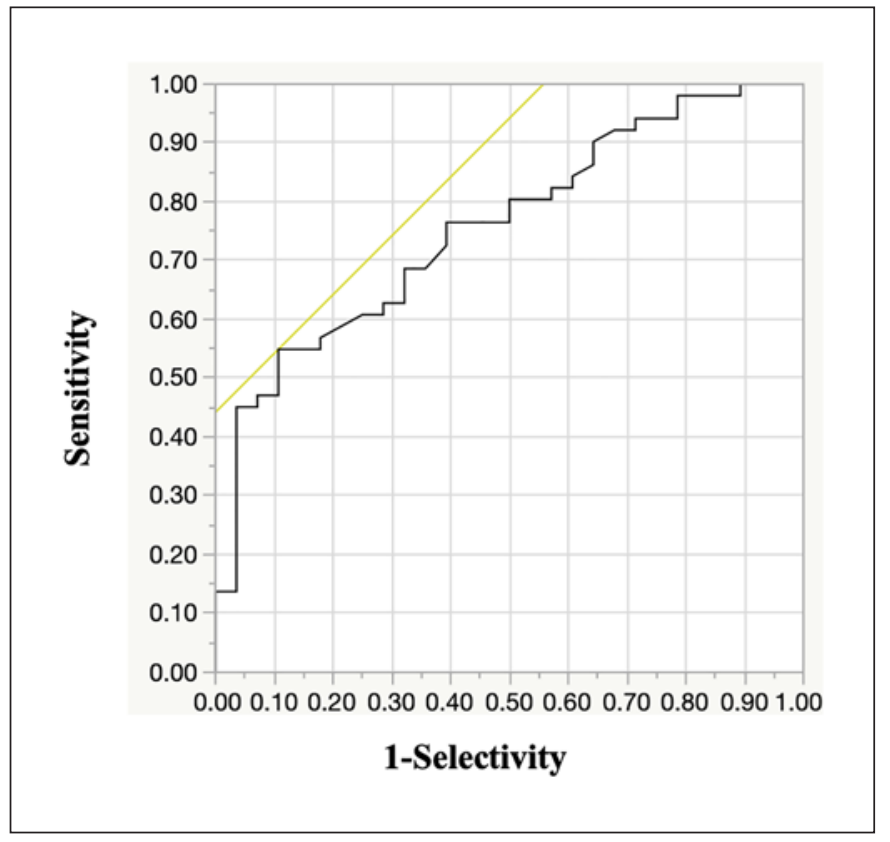

Fig. 1. Usefulness of plasma aldosterone level in the prediction of complete remission of type 2 diabetes (no or yes) 1 year after bariatric surgery. The curve represents the ROC curve for the prediction of complete remission of type 2 diabetes. The AUC of aldosterone exhibited the highest value (AUC; 0.7570). The sensitivity and specificity were the highest when the cutoff value for plasma aldosterone was $124.0 \mathrm{pg} / \mathrm{mL}$ (sensitivity, 54.9\%; specificity, $55.8 \%)$. The $95 \%$ CI was $0.6348-0.8481, p=0.0017$. AUC, area under the ROC curve; ROC, receiver operating characteristic; CI, confidence interval.

tion and insulin sensitivity, thus influencing type 2 diabetes remission. Therefore, we made two multiple regression models because of the influences of multicollinearity: one included sex, age, GGT, HbAlc, HOMA2-\%B, renin activity, and PAC (model 1), and the other included sex, age, GGT, renin activity, PAC, and duration of type 2 diabetes (model 2). Table 4 summarizes the results of the multiple regression analysis performed to identify the association between the CR of type 2 diabetes and other clinical variables. Model 1 showed that preoperative $\mathrm{HbA1c}, \mathrm{HOMA} 2-\% \mathrm{~B}$, and PAC were independent predictors of CR in type 2 diabetes after BS (HbA1c: standardized $\beta=0.2587, p=0.0266$; HOMA2$\% \mathrm{~B}$ : standardized $\beta=0.1973, p=0.0438$; PAC: standardized $\beta=-0.3712, p=0.0004)$. Model 2 showed that PAC and duration of type 2 diabetes were independent predictors of CR in type 2 diabetes after BS (PAC: standardized $\beta=-0.3295, p=0.0029$; duration of type 2 diabetes: standardized $\beta=-0.2461, p=0.0321$ ). PAC was the major independent predictor of CR in type 2 diabetes after BS. 
Table 4. Correlation of complete remission of type 2 diabetes (no, 0 ; yes, 1 ) with other preoperative variables analyzed by multiple regression models

\begin{tabular}{lllllll}
\hline & $\begin{array}{l}\text { Model 1 } \\
\text { standardized } \beta\end{array}$ & SE & $p$ value & $\begin{array}{l}\text { Model 2 } \\
\text { standardized } \beta\end{array}$ & SE & $p$ value \\
\hline Sex (male, 0; female, 1) & 0.1149 & 0.0977 & 0.2644 & 0.0662 & 0.1038 & 0.5436 \\
Age (years) & -0.0164 & 0.0056 & 0.8711 & 0.0153 & 0.0063 & 0.8939 \\
GGT (IU/L) & 0.1634 & 0.0010 & 0.1000 & 0.1161 & 0.0011 & 0.2706 \\
HbA1c (\%) & -0.2587 & 0.0334 & 0.0266 & - & - & - \\
HOMA2-\%B (\%) & 0.1973 & 0.0013 & 0.0438 & - & - & - \\
Renin activity (ng/mL/h) & -0.1778 & 0.0051 & 0.0752 & -0.1288 & 0.0054 & 0.2206 \\
Aldosterone (pg/mL) & -0.3712 & 0.0005 & 0.0004 & -0.3295 & 0.0005 & 0.0029 \\
Duration of type 2 diabetes (years) & - & - & - & -0.2461 & 0.0078 & 0.0321
\end{tabular}

Model 1: $r^{2}=0.3443, p<0.0001 ;$ model 2: $r^{2}=0.2424, p=0.0022$. SE, standard error; GGT, $\gamma$-glutamyl transpeptidase; HbA1c, glycosylated hemoglobin; HOMA, homeostasis model assessment.

Other variables at baseline were not found to be independent predictors of CR (Table 4).

\section{Usefulness of Baseline PAC in the Prediction of CR of}

Type 2 Diabetes (No, 0; Yes, 1) after BS

We attempted to use baseline PAC for the prediction of CR in type 2 diabetes (no or yes) after BS. The ROC curves show the fraction of true-positive results (sensitivity) and false-positive results at the cutoff PAC (Fig. 1). The cutoff value of PAC that yielded the maximal sensitivity and specificity was $124.0 \mathrm{pg} / \mathrm{mL}$. At this cutoff value, the sensitivity was $54.9 \%$, specificity was $55.8 \%$, and area under the ROC curve was 0.7570 . The ROC curve was significant $(p=0.0017)$ (Fig. 1).

Comparisons between Participants with Low $(<124.0$ $\mathrm{pg} / \mathrm{mL})$ and $\mathrm{High}(\geq 124.0 \mathrm{pg} / \mathrm{mL})$ PAC

We estimated the cutoff value of PAC for predicting the CR of type 2 diabetes after BS from the ROC curve (Fig. 1). We divided all participants into two groups: low aldosterone $(<124.0 \mathrm{pg} / \mathrm{mL})$ and high aldosterone $(\geq 124.0$ $\mathrm{pg} / \mathrm{mL}$ ) groups. Twenty-nine and 50 patients were included in the low and high PAC groups, respectively. PAC was significantly higher, and the rate of postoperative diabetes remission was significantly lower in the high aldosterone group than in the low aldosterone group (Table 5). Other parameters were not significantly different between the groups.

\section{Comparisons between SG Group and GB or SG with} DJB Group

Given the differences in the effects of SG and bypass procedures on glucose metabolism, we compared the SG group ( $n=62)$ and GB or SG with DJB group (bypass group) ( $n=17)$. Preoperative age, BW, BMI, PAC, and duration of type 2 diabetes were not different between the two groups. However, FBG and HbA1c were significantly higher in the bypass group than in the SG group (online suppl. Table 1; for all online suppl. material, see www. karger.com/doi/10.1159/000521855). There was a significant correlation between preoperative PAC and CR of type 2 diabetes (no, 0 ; yes, 1 ) in both groups (online suppl. Table 2). The correlation coefficient was -0.3796 ( $p=$ $0.0023)$ in the SG group and $-0.6281(p=0.0069)$ in the bypass group (online suppl. Table 2 ).

\section{Discussion/Conclusion}

In the present study, BS led to significant reductions in BW, BMI, FBG, and HbA1c levels. BS also significantly improved HOMA2-\%S and HOMA2-IR. The participants were divided into two groups: with $\mathrm{CR}$ and non-CR of type 2 diabetes. The PAC was significantly higher in participants with non-CR of type 2 diabetes. The multiple regression model showed that preoperative $\mathrm{HbA} 1 \mathrm{c}$ level, HOMA2-\%B, PAC, and duration of type 2 diabetes were independent predictors of CR in type 2 diabetes after BS. Preoperative PAC was the major independent predictor of CR in patients with type 2 diabetes after BS. The ROC curve showed that the cutoff value of PAC for CR of type 2 diabetes was $124.0 \mathrm{pg} / \mathrm{mL}$. The rate of CR of type 2 diabetes was significantly low in participants with $\geq 124.0 \mathrm{pg} /$ $\mathrm{mL}$ aldosterone.

Our study demonstrated that preoperative PAC was related to the CR of type 2 diabetes after BS. High aldosterone 
Table 5. Comparison of characteristics between participants with lower and higher plasma aldosterone concentration

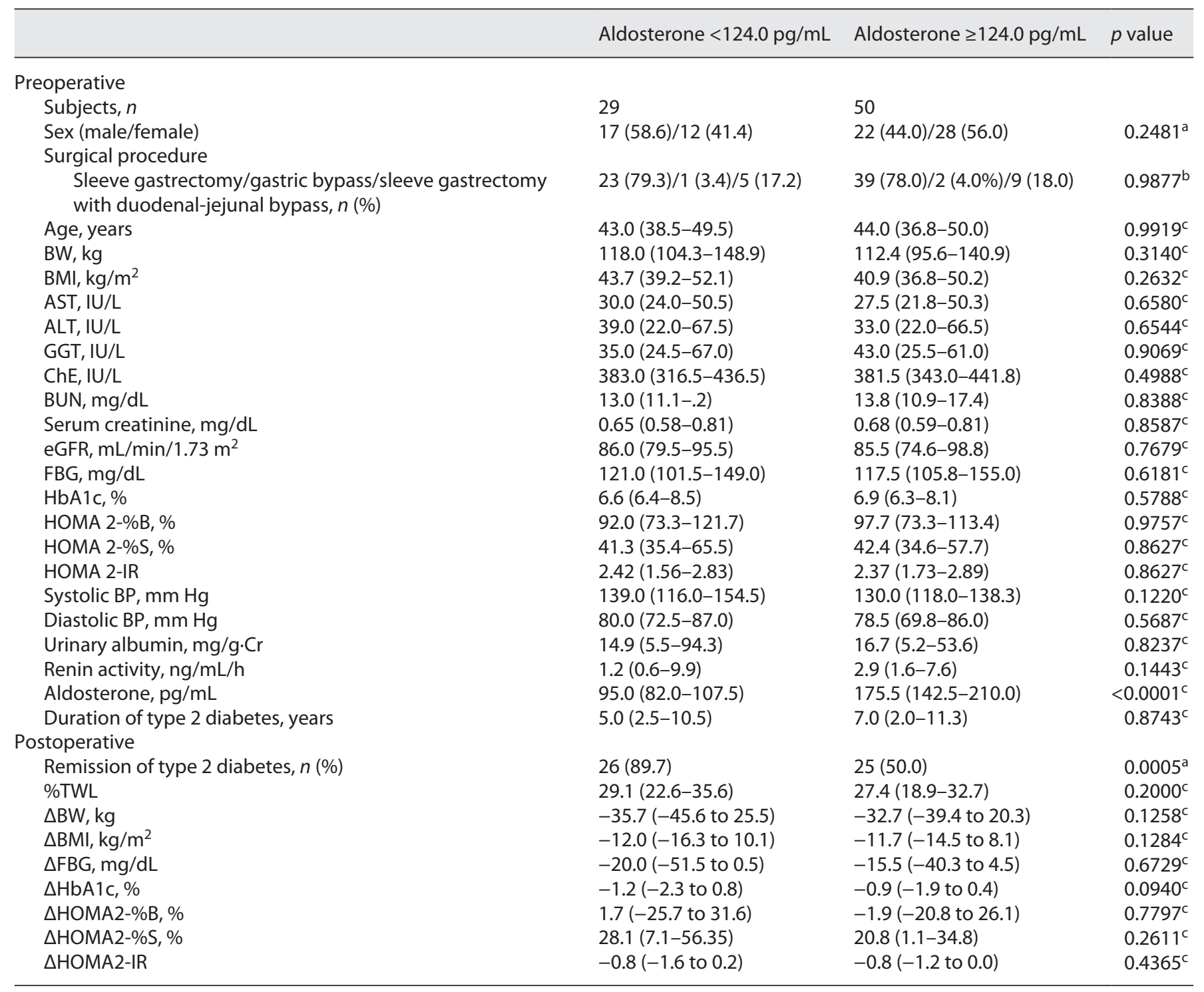

Data are presented as median and interquartile range. $\Delta$ represents the difference between the values at baseline and after 12 months. BW, body weight; BMI, body mass index; AST, aspartate transaminase; ALT, alanine transaminase; GGT, $\gamma$-glutamyl transpeptidase; ChE, cholinesterase; BUN, blood urea nitrogen; eGFR, estimated glomerular filtration rate; FBG, fasting blood glucose; HbA1c, glycosylated hemoglobin; HOMA, homeostasis model assessment; BP, blood pressure; TWL, total weight loss. ${ }^{a}$ Fisher's exact test. ${ }^{\mathrm{b}} \mathrm{X}^{2}$ test. ${ }^{\mathrm{C}} \mathrm{Wilcoxon}$ signed-rank test.

levels are associated with insulin resistance and incident type 2 diabetes. The prevalence of type 2 diabetes is high in patients with primary aldosteronism $[24,25]$. Some mechanisms of the association between aldosteronism and diabetes, especially insulin resistance, have been proposed. A decrease in aldosterone is related to a decrease in HOMAIR and an increase in adiponectin levels [26]. Aldosterone decreases adiponectin and diminishes the effect of rosigli- tazone on increasing adiponectin levels in 3T3-L1 adipocytes [27]. Aldosterone decreases insulin-induced glucose uptake by decreasing the phosphorylation of mitogen-activated protein kinase and Akt and by degradation of insulin receptor substrate (IRS) 1 and IRS 2 in cultured adipocytes [28, 29]. Aldosterone suppresses glucose transporter type 4 translocation in adipocytes and skeletal muscle [30]. Inhibition of the aldosterone effect via mineralocorticoid 
receptor inhibitors improves glucose uptake in skeletal muscle [31]. Thus, aldosterone is associated with insulin resistance in adipocytes and skeletal muscles. However, our study did not show a relationship between preoperative PAC and insulin resistance preoperatively and postoperatively. The mechanisms by which PAC relates to the $\mathrm{CR}$ of type 2 diabetes after BS are still unknown.

The mechanisms by which PAC relate to CR of type 2 diabetes were not clarified in the study. However, our results suggest that aldosterone blockade improves blood glucose in clinical situations. Eplerenone, a mineralocorticoid receptor antagonist, attenuates obesity-related insulin resistance, partly by reducing the production of reactive oxygen species, inflammatory processes, and induction of cytokines in obese mice [32]. Eplerenone also diminishes insulin resistance, partly by reducing the action of the renin-angiotensin-aldosterone system, inflammatory progression, and cytokine induction in mice [33]. Although aldosterone blockade improves insulin resistance in animal models, a meta-analysis showed that spironolactone has significant or nonsignificant negative effects. Eplerenone and canrenone have neutral effects on glycemia [34]. The relationship between blood glucose and esaxerenone, a newly developed mineralocorticoid blocker, has not been studied sufficiently. No patient in this study used mineralocorticoid blockers. Further studies are needed to clarify the effect of aldosterone blockade on type 2 diabetes.

Bypass procedures are associated with higher rates of type 2 diabetes remission than SG [7-11]. Some mechanisms that explain why diabetes improves after BS have been put forth; an increase in GLP-1 secretion after BS is one of such mechanisms [35]. GLP-1 secretion is increased after bypass procedures and SG, and the effect is stronger in bypass procedures than in SG [36]. Both GLP1 and insulin secretion at $30 \mathrm{~min}$ after a meal test are significantly increased after RYGB [37]; GB is associated with a greater increase in insulin secretion in the oral glucose tolerance test than SG, which may explain type 2 diabetes remission after BS [38]. Furthermore, GLP-1 suppresses PAC [39]; aldosterone is known to reduce insulin secretion [40]. PACs decrease after GB [41]. Therefore, suppression of PAC by increasing GLP-1 secretion may be a mechanism of increase of insulin secretion after BS. PACs may reduce more with bypass procedures than SG because bypass procedures increase GLP-1 secretion than SG [36]. The correlation coefficient between type 2 diabetes remission after surgery and preoperative PAC was 1.6-fold higher in bypass procedures than in SG in this study. The relationship between GLP-1, aldosterone, and insulin secretion may be one of the mechanisms that explain the higher remission rates of type 2 diabetes after BS in bypass procedures than in SG. However further study is needed to clarify this mechanism.

Our study showed that preoperative insulin secretion is related to the CR of type 2 diabetes after BS. Other studies and our previous study have also shown that higher preoperative serum C-peptide levels or better $\beta$-cell function are associated with type 2 diabetes remission after BS $[12,15,42-44]$. Higher insulin secretion represents the preservation of $\beta$-cell function. Although BS improves type 2 diabetes, the recovery of $\beta$-cell function is limited after RYGB [45]. Thus, sufficient preoperative insulin secretion is necessary for the CR of type 2 diabetes after BS.

This study has a few limitations. First, PAC was not measured in any patient after BS. If PAC was measured in all patients after BS, we would have been able to determine whether PAC decreased after BS. Further prospective research is needed to clarify changes in plasma renin activity and PAC after BS. Second, there were three types of surgeries in this study; the rates of CR for type 2 diabetes were $64.5 \%(40 / 62), 66.7 \%(2 / 3)$, and $64.3 \%(9 / 14)$ in patients who underwent SG, GB, and SG with DJB, respectively. Although there was no significant difference in the CR rates between the surgery types, the patients with type 2 diabetes in this study who underwent bypass procedures had more severe disease than those who underwent SG. However, the rates of types of surgical procedures were not different between the low and high PAC groups. Finally, as this was a single-center retrospective study, the sample size was small. Future studies with a large number of patients with obesity, a control group, and use of multiple medical centers in Japan and possibly other Asian countries are needed. Despite these limitations, we were able to show that preoperative PAC was a predictor of CR in type 2 diabetes after BS.

In conclusion, preoperative PAC is related to the $\mathrm{CR}$ of type 2 diabetes after BS. Measuring PAC preoperatively is useful for predicting the CR of type 2 diabetes after BS. However, the mechanisms by which preoperative PAC is related to the CR of type 2 diabetes and changes in plasma renin activity and PAC after BS are still unknown. Further studies are needed to clarify these.

\section{Acknowledgment}

The authors are grateful to Sayaka Tsuji (Center for Diabetes, Endocrinology and Metabolism, Toho University Sakura Medical Center, Sakura-City, Chiba, Japan), a coordinator, for her assistance with patient care. 


\section{Statement of Ethics}

The protocol of the study was prepared in accordance with the Declaration of Helsinki and was approved by the Ethics Committee of the Toho University Sakura Medical Center (approval date: November 28, 2018; Approval No. S18061). Our institute waived the need to obtain written informed consent due to the retrospective study design.

\section{Conflict of Interest Statement}

The authors have no conflicts of interest to declare.

\section{Funding Sources}

The authors did not receive any funding.

\section{Author Contributions}

M.O. contributed to the research concept and design, collection and/or assembly of data, data analysis, and writing of the article. K.A. contributed to the collection and assembly of data. T.Y. contributed to the collection and assembly of data. H.O. contributed to the collection and assembly of data. S.Y. contributed to the collection and assembly of data. S.N. contributed to the collection and assembly of data. S.T. contributed to the collection and assembly of data. Y.W. contributed to the collection and assembly of data. T.N. contributed to the collection and assembly of data. T.O. contributed to the collection and assembly of data. D.N. contributed to data interpretation. A.S. contributed to the collection and/ or assembly of the data and critical revision of the manuscript. I.T. contributed to data interpretation and critical revision of the manuscript. All authors approved the version to be published.

\section{Data Availability Statement}

Data generated and/or analyzed during this research are available from the corresponding author on reasonable request.

\section{References}

1 Schauer PR, Bhatt DL, Kirwan JP, Wolski K, Aminian A, Brethauer SA, et al. Bariatric surgery versus intensive medical therapy for diabetes: 5-year outcomes. N Engl J Med. 2017 Feb;376(7):641-51.

2 Sjöström L, Peltonen M, Jacobson P, Ahlin S, Andersson-Assarsson J, Anveden Å, et al. Association of bariatric surgery with long-term remission of type 2 diabetes and with microvascular and macrovascular complications. JAMA. 2014 Jun;311(22):2297-304.

3 Lee MH, Lee WJ, Chong K, Chen JC, Ser KH, Lee YC, et al. Predictors of long-term diabetes remission after metabolic surgery. J Gastrointest Surg. 2015 Jun;19(6):1015-21.

4 Rubino F, Nathan DM, Eckel RH, Schauer PR, Alberti KG, Zimmet PZ, et al. Metabolic surgery in the treatment algorithm for type $2 \mathrm{di}$ abetes: a joint statement by international diabetes organizations. Diabetes Care. 2016 Jun; 39(6):861-77.

5 Li YX, Fang DH, Liu TX. Laparoscopic sleeve gastrectomy combined with single-anastomosis duodenal-jejunal bypass in the treatment of type 2 diabetes mellitus of patients with body mass index higher than $27.5 \mathrm{~kg} / \mathrm{m} 2$ but lower than $32.5 \mathrm{~kg} / \mathrm{m} 2$. Medicine. 2018 Aug;97(31):e11537.

6 Billeter AT, Eichel S, Scheurlen KM, Probst P, Kopf S, Müller-Stich BP. Meta-analysis of metabolic surgery versus medical treatment for macrovascular complications and mortality in patients with type 2 diabetes. Surg Obes Relat Dis. 2019 Jul;15(7):1197-210.

7 McTigue KM, Wellman R, Nauman E, Anau J, Coley RY, Odor A, et al. Comparing the 5 -year diabetes outcomes of sleeve gastrectomy and gastric bypass: the national patientcentered clinical research network (PCOR-
Net) bariatric study. JAMA Surg. 2020 May; 155(5):e200087.

8 Castellana M, Procino F, Biacchi E, Zupo R, Lampignano L, Castellana F, et al. Roux-en-Y gastric bypass vs sleeve gastrectomy for remission of type 2 diabetes. J Clin Endocrinol Metab. 2021 Mar;106(3):922-33.

9 Hofsø D, Fatima F, Borgeraas H, Brikeland KI, Gulseth HL, Hertel JK, et al. Gastric bypass versus sleeve gastrectomy in patients with type 2 diabetes (Oseberg): a single-centre, triple-blind, randomised controlled trial. Lancet Diabetes Endocrinol. 2019 Dec;7(12): 912-24.

10 Seki Y, Kasama K, Haruta H, Watanabe A, Yokoyama R, Porciuncula JPC, et al. Fiveyear-results of laparoscopic sleeve gastrectomy with duodenojejunal bypass for weight loww and type 2 diabetes mellitus. Obes Surg. 2017 Mar;27(3):795-801.

11 Praveen Raj P, Kumaravel R, Chandramaliteeswaran C, Rajpandian S, Palanivelu C. Is laparoscopic duodenojejunal bypass with sleeve an effective alternative to Roux en $\mathrm{Y}$ gastric bypass in morbidly obese patients: preliminary results of a randomized trial. Obes Surg. 2012 Mar;22(3):422-6.

12 Wang GF, Yan YX, Xu N, Yin D, Hui Y, Zhang JP, et al. Predictive factors of type 2 diabetes mellitus remission following bariatric surgery: a meta-analysis. Obes Surg. 2015 Feb; 25(2):199-208.

13 Panunzi S, Carlsson L, De Gaetano A, Peltonen M, Rice T, Sjöström L, et al. Determinants of diabetes remission and glycemic control after bariatric surgery. Diabetes Care. 2016 Jan;39(1):166-74.

14 Lee WJ, Chong K, Chen JC, Ser KH, Lee YC, Tsou JJ, et al. Predictors of diabetes remission after bariatric surgery in Asia. Asian J Surg. 2012 Apr;35(2):67-73.

15 Dixon JB, Chuang LM, Chong K, Chen SC, Lambert GW, Straznicky NE, et al. Predicting the glycemic response to gastric bypass surgery in patients with type 2 diabetes. Diabetes Care. 2013 Jan;36(1):20-6.

16 Ohira M, Watanabe Y, Yamaguchi T, Saiki A, Oshiro T, Tatsuno I. Low serum insulin-like growth factor-1 level is a predictor of low total weight loss percentage after sleeve gastrectomy. Surg Obes Relat Dis. 2020 Dec;16(12):1978-87.

17 Mazziotti G, Gazzaruso C, Giustina A. Diabetes in cushing syndrome: basic and clinical aspects. Trends Endocrinol Metab. 2011 Dec; 22(12):499-506.

18 Kim SH, Park MJ. Effects of growth hormone on glucose metabolism and insulin resistance in human. Ann Pediatr Endocrinol Metab. 2017 Sep;22(3):145-52.

19 Luther JM. Effects of aldosterone on insulin sensitivity and secretion. Steroids. 2014 Dec; 91:54-60.

20 Oshiro T, Kasama K, Nabekura T, Sato Y, Kitahara T, Matsunaga $\mathrm{R}$, et al. Current status and issue associated with bariatric and metabolic surgeries in Japan. Obes Surg. 2021 Jan; 31(1):343-9.

21 Brethauer SA, Kim J, el Chaar M, Papasavas P, Eisenberg D, Rogers A, et al. Standardized outcomes reporting in metabolic and bariatric surgery. Surg Obes Relat Dis. 2015 MayJun;11(3):489-506.

22 Saiki A, Yamaguchi T, Tanaka S, Sasaki A, Naitoh T, Seto Y, et al. Background characteristics and postoperative outcomes of insufficient weight loss after laparoscopic sleeve gastrectomy in Japanese patients. Ann Gastroenterol Surg. 2019 Aug;3(6):638-47. 
23 Wallace TM, Levy JC, Matthews DR. Use and abuse of HOMA modeling. Diabetes Care. 2004 Jun;27(6):1487-95.

24 Joseph JJ, Echouffo Tcheugui JB, Effoe VS, Hsueh WA, Allison MA, Golden SH. Reninangiotensin-aldosterone system, glucose metabolism and incident type 2 diabetes mellitus: MESA. J Am Heart Assoc. 2018 Sep; 7(17): e009890.

25 Akehi Y, Yanase T, Motonaga R, Umakoshi $H$, Tsuiki M, Takeda Y, et al. High prevalence of diabetes in patients with primary aldosteronism (PA) associated with subclinical hypercortisolism and prediabetes more prevalent in bilateral than unilateral PA: A large, multicenter cohort study in Japan. Diabetes Care. 2019 May;42(5):938-45.

26 Cooper JN, Fried L, Tepper P, Barinas-Mitchell E, Conroy MB, Evans RW, et al. Changes in serum aldosterone are associated with changes in obesity-related factors in normotensive overweight and obese young adults. Hypertens Res. 2013 Oct;36(10):895-901.

27 Li P, Zhang XN, Pan CM, Sun F, Zhu DL, Song HD, et al. Aldosterone perturbs adiponectin and PAI-1 expression and secretion in 3T3-L1 adipocytes. Horm Metab Res. 2011 Jun;43(7):464-9.

28 Kraus D, Jäger J, Meier B, Fasshauer M, Klein J. Aldosterone inhibits uncoupling protein-1, induces insulin resistance, and stimulates proinflammatory adipokines in adipocytes. Horm Metab Res. 2005 Jul;37(7):455-9.

29 Wada T, Ohshima S, Fujisawa E, Koya D, Tsuneki H, Sasaoka T. Aldosterone inhibits insulin-induced glucose uptake by degradation of insulin receptor substrate (IRS) 1 and IRS2 via a reactive oxygen species-mediated pathway in 3T3-L1 adipocytes. Endocrinology. 2009 Apr; 150(4):1662-9.

30 Underwood PC, Adler GK. The renin angiotensin aldosterone system and insulin resistance in humans. Curr Hypertens Rep. 2013 Feb;15(1):59-70.
31 Goossens GH. The renin-angiotensin system in the pathophysiology of type 2 diabetes. Obes Facts. 2012;5(4):611-24.

32 Hirata A, Maeda N, Hiuge A, Hibuse T, Fujita $\mathrm{K}$, Okada $\mathrm{T}$, et al. Blockade of mineralocorticoid receptor reverses adipocyte dysfunction and insulin resistance in obese mice. Cardiovasc Res. 2009 Oct;84(1):164-72.

33 Vecchiola A, Fuentes CA, Solar I, Lagos CF, Opazo MC, Muñoz-Durango N, et al. Eplerenone implantation improved adipose dysfunction averting RAAS activation and cell division. Front Endocrinol. 2020 Apr;11:223.

34 Korol S, Mottet F, Perreault S, Baker WL, White M, de Denus S. A systematic review and meta-analysis of the impact of mineralocorticoid receptor antagonists on glucose homeostasis. Medicine. 2017 Dec;96(48):e8719.

35 Casajoana A, Guerrero-Pérez F, García Ruiz de Gordejuela A, Admella V, Sorribas M, Vidal-Alabró A, et al. Role of gastrointestinal hormones as a predictive factor for long-term diabetes remission: randomized trial comparing metabolic gastric bypass, sleeve gastrectomy, and greater curvature plication. Obes Surg. 2021 Apr;31(4):1733-44.

36 Roushdy A, Abdel-Razik MA, Emile SH, Farid M, Elbanna HG, Khafagy W, et al. Fasting ghrelin and postprandial GLP-1 levels in patients with morbid obesity and medical comorbidities after sleeve gastrectomy and oneanastomosis gastric bypass: a randomized clinical trial. Surg Laparosc Endosc Percutan Tech. 2020 Aug;31(1):28-35.

37 Umeda LM, Silva EA, Carneiro G, Arasaki $\mathrm{CH}$, Geloneze B, Zanella MT. Early improvement in glycemic control after bariatric surgery and its relationships with insulin, GLP-1, and glucagon secretion in type 2 diabetic patients. Obes Surg. 2011 Jul;21(7):896-901.

38 Chen CY, Lee WJ, Asakawa A, Fujitsuka N, Chong K, Chen SC, et al. Insulin secretion and interleukin-1beta dependent mechanisms in human diabetes remission after metabolic surgery. Curr Med Chem. 2013;20(18):2374-88.
39 Baretić M, Kušec V, Pavlić-Renar I. Glucagon-like peptide-1 infusion suppresses aldosterone levels in healthy normal-weight individuals: double-blind, placebo-controlled crossover study. Diabetes Ther. 2018 Dec; 9(6):2315-24.

40 Goto R, Kondo T, Ono K, Kitano S, Miyakawa $\mathrm{N}$, Watanabe T, et al. Mineralocorticoid receptor may regulate glucose homeostasis through the induction of interleeukin- 6 and Glucagon-like peptide-1 in pancreatic islets. J Clin Med. 2019 May;8(5):674.

41 Suwannasrisuk P, Boonchaya-Anant P, Houngngam N, Udomsawaengsup S, Sunthornyothin S. Changes in plasma aldosterone level after weight loss by bariatric surgery in morbidly obese patients. BMC Endocr Disord. 2020 Apr;20(1):45.

42 Ohira M, Watanabe Y, Yamaguchi T, Saiki A, Nakamura S, Tanaka S, et al. Determinants of type 2 diabetes remission after bariatric surgery in obese Japanese patients: A retrospective cohort study. Diabetol Int. 2021;12(4): 379-88.

43 Lee WJ, Chong K, Ser KH, Chen JC, Lee YC, Chen SC, et al. C-peptide predicts the remission of type 2 diabetes after bariatric surgery. Obes Surg. 2012 Feb;22(2):293-8.

44 Chong K, Ikramuddin S, Lee WJ, Billington CJ, Bantle JP, Wang Q, et al. National differences in remission of type 2 diabetes mellitus after Roux-en-Y gastric bypass surgery-subgroup analysis of 2-year results of the diabetes surgery study comparing Taiwanese with Americans with mild obesity (BMI $30-35 \mathrm{~kg} /$ m2). Obes Surg. 2017 May;27(5):1189-95.

45 Dutia R, Brakoniecki K, Bunker P, Paultre F, Homel P, Carpentier AC, et al. Limited recovery of beta-cell function after gastric bypass despite clinical diabetes remission. Diabetes. 2014 Apr;63(4):1214-23. 